\title{
Influence of initial annealing on structure evolution and magnetic properties of 3.4\% Si non-oriented steel during final annealing
}

\author{
Josiane Simões Mendanha Pedrosa ${ }^{a}$, Sebastião da Costa Paolinelli ${ }^{\mathrm{b}}$, André Barros Cota ${ }^{\mathrm{a}, *}$ \\ a Department of Physics, Federal University of Ouro Preto, Ouro Preto MG-3540000, Brazil \\ ${ }^{\mathrm{b}}$ Research Department Aperam South America, Praça Primeiro de Maio, 9, Timóteo MG-35180018, Brazil
}

\section{A R T I C L E I N F O}

\section{Article history:}

Received 2 March 2015

Received in revised form

23 April 2015

Accepted 3 May 2015

Available online 22 May 2015

Keywords:

Non-oriented electrical steel

Initial annealing

Shear bands

Texture

Magnetic properties

\begin{abstract}
A B S T R A C T
The effect of the initial annealing on structure evolution and magnetic properties during the final annealing of a $3.4 \% \mathrm{Si}$ non-oriented grain steel was evaluated. Half of the samples were submitted to initial annealing at $1030^{\circ} \mathrm{C}$ before cold rolling and all samples were subjected to final annealing process at temperatures from $540{ }^{\circ} \mathrm{C}$ to $1100{ }^{\circ} \mathrm{C}$. The magnetic induction and core loss in the final samples, the microstructure by optical microscopy and the crystallographic texture by X-ray diffraction and EBSD were evaluated. The results show that the samples without initial annealing presented better magnetic properties than the samples with initial annealing, due to the higher ratio between Eta fiber and Gamma fiber volume fractions (Eta/Gamma ratio) in their structure after final annealing.
\end{abstract}

(c) 2015 Elsevier B.V. All rights reserved.

\section{Introduction}

In many applications of non-oriented electrical steels, high magnetic permeability and low core loss are important characteristics. The magnetic properties of these steels depend on the grain size and crystallographic texture after the final annealing, resulting from the control of chemical composition and thermomechanical processing parameters [1-3].

The intense generation of shear bands in the deformed material before the final annealing is important for the formation of grains with Cube and Goss textures (Eta fiber components) in electrical steels $[4,5]$. It has been found that the increase of hot band grain size increases the tendency to formation of shear bands during cold rolling and promotes an increase in the Eta fiber volume fraction and a decrease of grain boundary area, hindering the Gamma fiber nucleation in annealing. This causes improvement in the magnetic induction [6-10].

It has been observed that the initial annealing before cold rolling is effective in generating a more homogeneous structure and with a larger grain size of the hot band sample, that causes an increase in magnetic induction associated with the increase of Eta fiber volume fraction and the reduction in the Gamma fiber volume fraction in the structure after the final annealing. Yashiki and Kaneko [11] reported that hot band annealing at higher

\footnotetext{
* Corresponding author.

E-mail address: abcota@ufop.br (A.B. Cota).
}

temperature of $850{ }^{\circ} \mathrm{C}$ was very effective to obtain both high magnetic induction and low core loss in a $0.34 \% \mathrm{Si}$ non-oriented grain steel. Paolinelli and Cunha [12] showed that industrial hot band samples of a $1.39 \% \mathrm{Si}$, finished in a Steckel mill at $1000{ }^{\circ} \mathrm{C}$, resulted in a more favorable final structure and better magnetic properties due to larger grain size after hot band annealing, what is known to favor formation of shear bands in cold rolling. Park and Szpunar [13] studied the effect of initial grain size prior to cold rolling on the texture evolution and magnetic properties in $2 \% \mathrm{Si}$ non-oriented grain steel and they observed that the magnetic induction of the coarse-grained samples was higher and the core loss was lower at the same temperature than that of the finegrained samples.

In this work, the influence of the initial annealing on grain structure, the crystallographic texture evolution and magnetic properties during the final annealing of industrial hot band samples of a $3.4 \%$ Si non-oriented electrical steel, finished in a Steckel mill, was investigated.

\section{Experiment}

Samples of non-oriented grain steel with $1.7 \mathrm{~mm}$ thickness, with $0.003 \%$ C, 3.4\% Si, 0.59\% Mn, 0.0035\% Al, 0.011\% P, 0.003\% Nb, $0.003 \% \mathrm{Ti}$ and $0.003 \% \mathrm{~N}$, were used in this study. This material was industrially produced by Aperam South America.

Half of the samples were annealed at $1030^{\circ} \mathrm{C} / 30 \mathrm{~s}$ and all were 
cold rolled to $0.50 \mathrm{~mm}$. The final annealing was carried out at temperatures in the range from $540{ }^{\circ} \mathrm{C}$ to $1100{ }^{\circ} \mathrm{C}$ for $30 \mathrm{~s}$, in $0 \%$ $\mathrm{H}_{2}+100 \% \mathrm{~N}_{2}$ atmosphere in the range $540-780{ }^{\circ} \mathrm{C}$ and in $75 \%$ $\mathrm{H}_{2}+25 \% \mathrm{~N}_{2}$ atmosphere in the range $820-1100{ }^{\circ} \mathrm{C}$, with a dew point below $-30^{\circ} \mathrm{C}$.

The grain size was determined by optical microscopy. The crystallographic orientation and volume fractions of the fibers and components texture were obtained by X-ray diffraction and Electron Back-Scattering Diffraction (EBSD). The magnetic induction at $5000 \mathrm{~A} / \mathrm{m}\left(B_{50}\right)$ and core loss at $1.5 \mathrm{~T} / 60 \mathrm{~Hz}\left(W_{15 / 60}\right)$ were measured after the final annealing in the rolling direction using the single sheet accessory of Brockhaus MPG100D equipment.

\section{Results and discussion}

\subsection{Initial annealing and cold rolling}

Fig. 1a and b shows the microstructures of the samples with and without initial annealing, respectively. The sample with initial annealing showed homogeneous grains with an average grain size of $180 \mu \mathrm{m}$. The sample without initial annealing has an average grain size of $109 \mu \mathrm{m}$ and smaller grains close to the surface (Fig. 1b), which were possibly formed by recrystallization after the last pass in the Steckel mill, with its growth interrupted by the rapid strip cooling. The microstructures of the samples cold rolled are shown in Fig. 1c and d. The microstructures are constituted of elongated grains, deformation bands and shear bands.

The volume fraction values of the main fibers and Cube component obtained by X-ray diffraction are shown in Fig. 2. The initial annealing decreased the Alpha, Theta, Gamma fibers and Cube component volume fractions, and the Eta fiber volume fraction tends to maintain stability.

A higher Gamma fiber volume fraction before cold rolling is interesting because grains with this orientation store more energy during cold work and increase the tendency to generate shear bands, favoring the nucleation of grains with Goss and Cube orientations during the final annealing [4,9,14].

The influence of cold deformation on volume fractions of the main fibers and Cube component of samples with and without initial annealing is shown in Fig. 3. The sample without initial annealing has a higher Gamma fiber volume fraction and a smaller Alpha fiber fraction than the sample with initial annealing. The lowest Alpha fiber volume fraction in the deformed material is another important factor because the grains that have this orientation store little energy during cold deformation and reduce

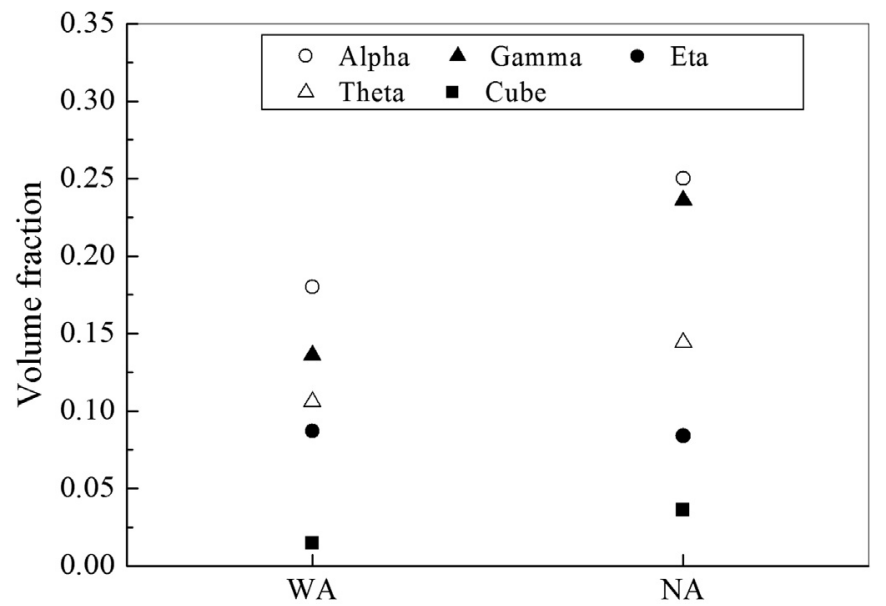

Fig. 2. Volume fraction of the fibers and Cube component of hot band samples with (WA) and without initial annealing (NA).

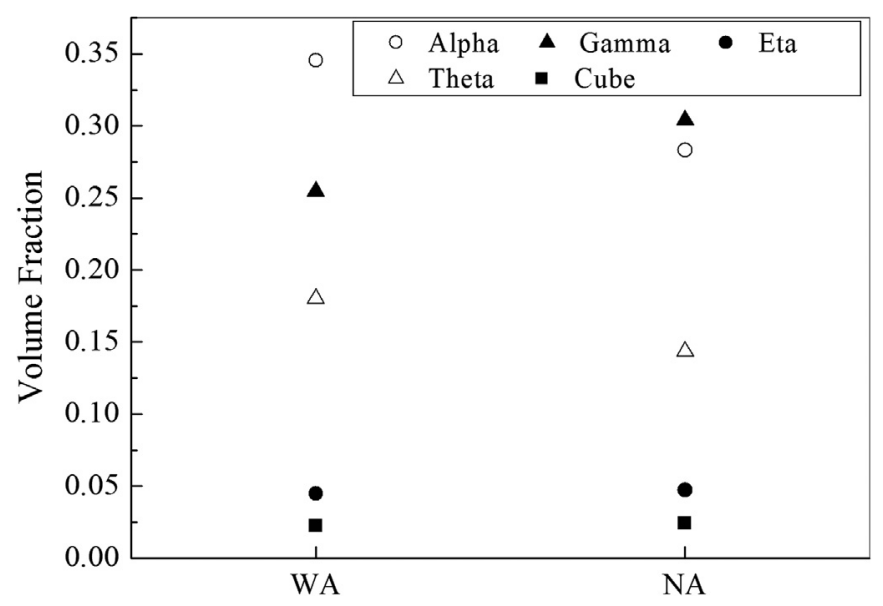

Fig. 3. Volume fraction of the fibers and Cube component of samples with initial annealing (WA) and without initial annealing (NA) after cold rolling.

the probability of grain nucleation with orientations belonging to Gamma fiber during final annealing $[15,16]$.

\subsection{Final annealing}

The grain size evolution of samples with and without initial annealing as a function of the final annealing temperature is
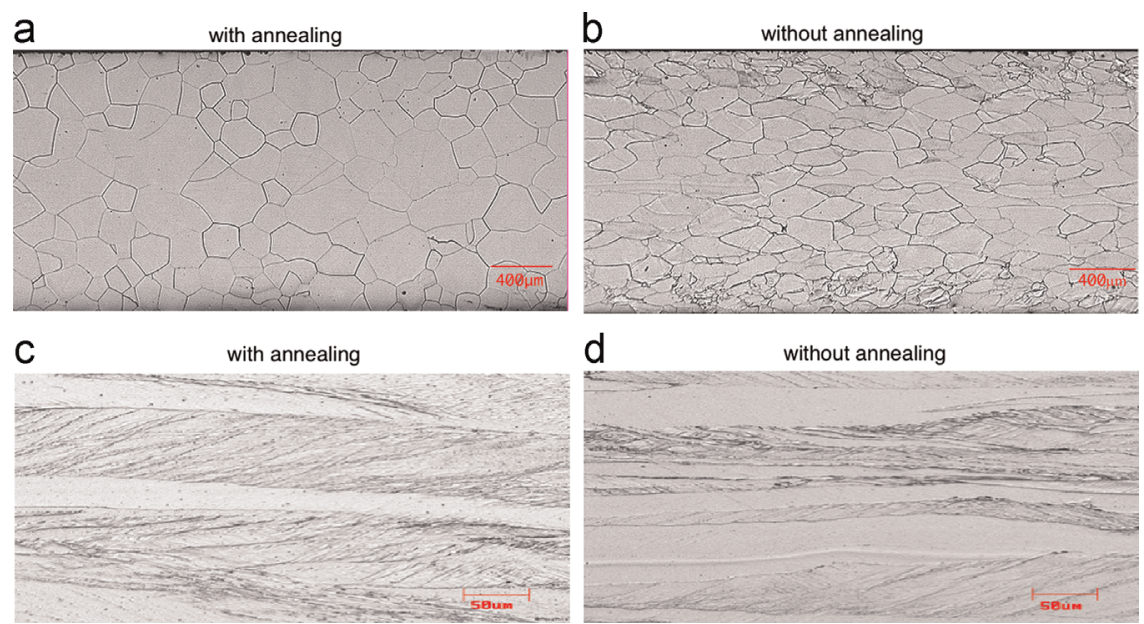

Fig. 1. Optical microstructures of hot bands (a) with initial annealing at $1030^{\circ} \mathrm{C} / 30 \mathrm{~s}$ and (c) cold rolling; (b) without initial annealing and (d) cold rolling. 


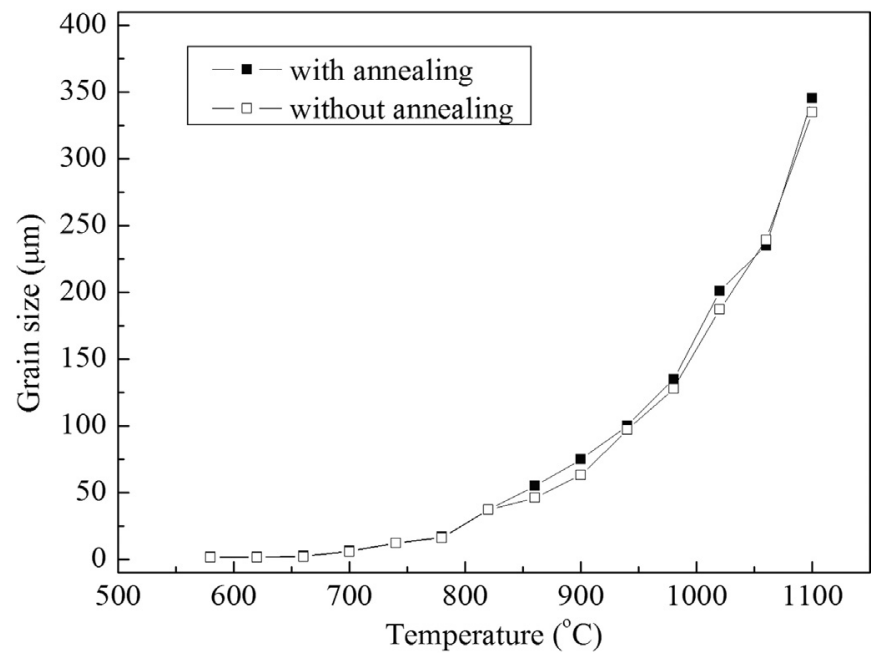

Fig. 4. Grain size of samples with and without initial annealing as a function of the final annealing temperature.

shown in Fig. 4. The samples with and without initial annealing had a similar grain growth behavior and they do not have significant different grain sizes at final annealing temperatures. As the final grain size has a great influence on magnetic properties, especially the core loss, the differences between the magnetic properties should only be related to the crystallographic texture of the samples with and without initial annealing.

The Gamma fiber volume fraction decreases with the increase of the final annealing temperature in the samples with (Fig. 5) and without initial annealing (Fig. 6). The variation of Eta fiber volume fraction has the same behavior in samples with and without annealing. It is noted that the volume fraction of this fiber has a sharp increase during the recrystallization process up to the temperature of $780{ }^{\circ} \mathrm{C}$ when the recrystallization finishes and grain growth starts. The Eta fiber volume fraction was higher in the samples without initial annealing and its decrease with the final annealing temperature occurs more slowly than the samples submitted to initial annealing.

Figs. 7 and 8 show the shear band contributions to form the crystallographic texture in the samples with and without initial annealing, respectively. Most of the grains nucleated in the shear bands belong to the Eta fiber. These grains maintain the

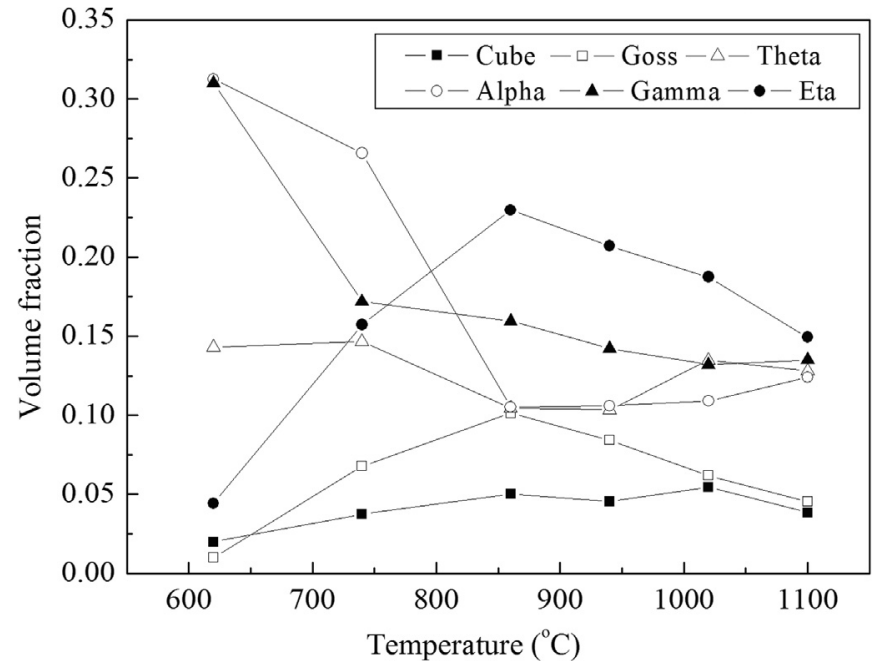

Fig. 5. Volume fractions of the Alpha, Gamma, Eta, Theta fibers, and Goss and Cube components in the samples with initial annealing as a function of the final annealing temperature.

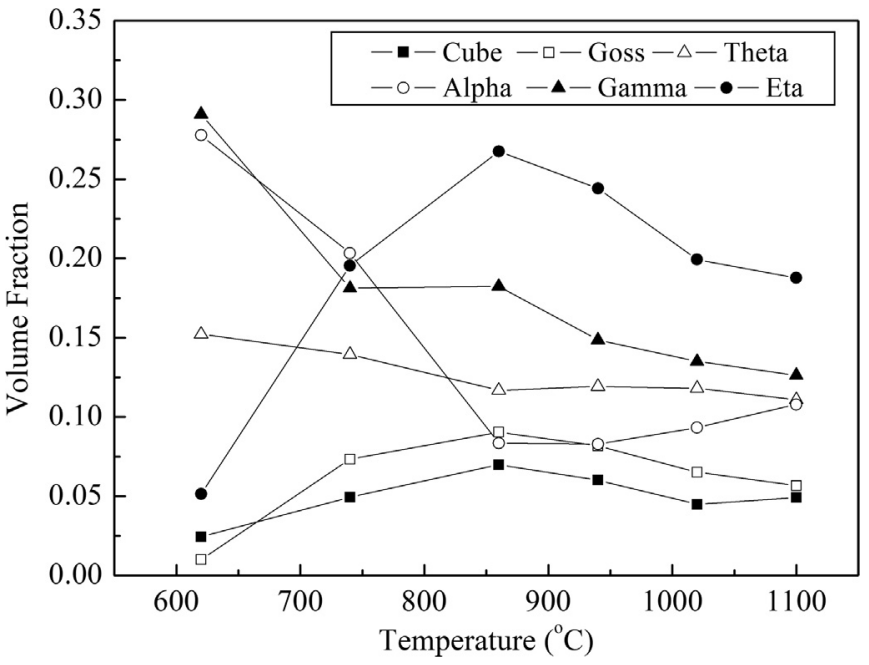

Fig. 6. Volume fractions of the Alpha, Gamma, Eta, Theta fibers, and Goss and Cube components in the samples without initial annealing as a function of the final annealing temperature.

disposition of shear bands where they were nucleated until the end of primary recrystallization. The Eta volume fraction decreases during further grain growth stage with the increase of the final annealing temperature, due to the nucleation of other grains having other orientations, formed in other nucleation sites such as grain boundaries.

The texture factor or Eta/Gamma ratio, defined as the ratio of Eta fiber to Gamma fiber volume fraction, is an important parameter to evaluate the texture effectiveness in improving the magnetic properties. Fig. 9 shows this factor as a function of the final annealing temperature for the samples with and without initial annealing. It can be observed that the texture factor has a favorable behavior to the sample without initial annealing. The highest texture factor for samples without initial annealing is associated with higher Gamma fiber volume fraction before the cold deformation and smaller Alpha fiber fraction after cold deformation of the samples with initial annealing.

\subsection{Magnetic properties}

Fig. 10 shows the magnetic induction at $5000 \mathrm{~A} / \mathrm{m}\left(B_{50}\right)$ measured in the rolling direction of samples with and without initial annealing as a function of the final annealing temperature. The samples with higher magnetic induction were those not submitted to initial annealing.

The results of magnetic induction $\left(B_{50}\right)$ are explained by the texture found in the material with and without annealing. The samples without initial annealing have a more favorable texture, evidenced by higher texture factor, resulting in higher magnetic induction.

Grain growth after recrystallization has a beneficial effect on core loss at $1.5 \mathrm{~T} / 60 \mathrm{~Hz}\left(W_{15 / 60}\right)$ (Fig. 11). Due to the opposite effects of grain size on hysteresis and anomalous losses, there is an optimum grain size around $180-200 \mu \mathrm{m}$ that minimizes the core loss. It can be observed that the samples without initial annealing have smaller core loss than the samples that were annealed. As the final grain size of the samples with and without annealing is practically the same (Fig. 4), the difference in the crystallographic textures can explain the core loss values of these samples. The samples without initial annealing have a lower core loss at higher annealing temperatures due to higher texture factor.

The initial annealing in the hot band samples has deteriorated the magnetic properties of the steel. This can be explained by the 
a

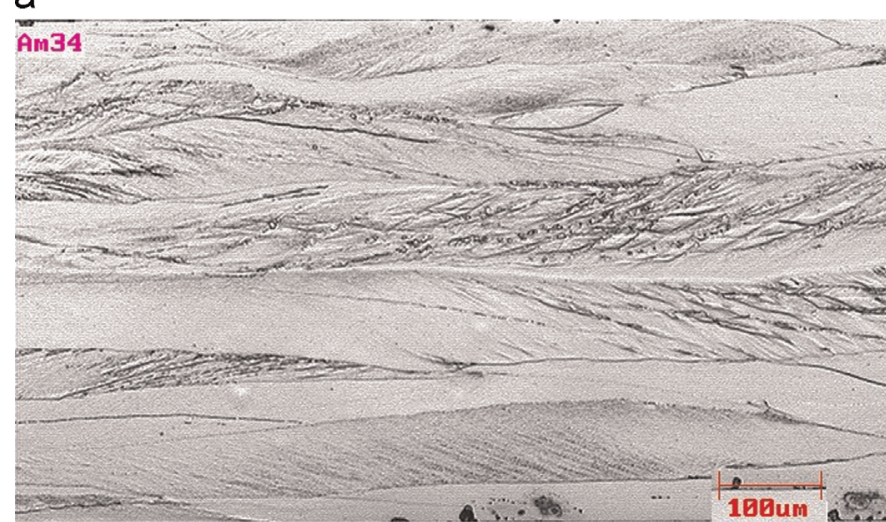

b

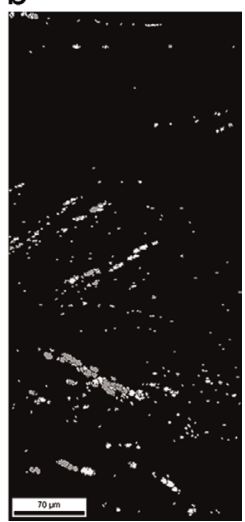

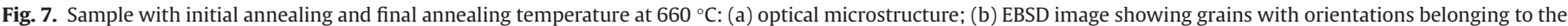
Eta fiber (gray) nucleated in the shear bands.

initial structure of the hot band sample. With initial annealing, there was an increase in the average grain size of $109 \mu \mathrm{m}$ (sample without initial annealing) to $190 \mu \mathrm{m}$. The increase in the grain size with initial annealing before the cold rolling resulted in a smaller Gamma fiber volume fraction after the deformation than the sample without initial annealing and a lower tendency to form shear bands. As a result, the nucleation occurs more in grain boundary, reducing the texture factor by decreasing the Eta fiber volume fraction and increasing the Gamma fraction, deteriorating the magnetic properties. Furthermore, it is known that there is an optimum grain size for each cold reduction or hot band thickness, which results in maximum shear bands formation as well as maximum texture factor, as previously reported by the authors [17]. The material without annealing shows close to optimal grain size, considering the cold reduction corresponding to a hot band sample with $1.7 \mathrm{~mm}$. When the sample is submitted to the initial annealing, the grain size is increased to $190 \mu \mathrm{m}$, exceeding the optimum value, resulting in a minor texture factor.

\section{Conclusions}

The initial annealing applied to hot band samples with $3.4 \% \mathrm{Si}$ non-oriented electrical steel increased the grain size from 109 to $190 \mu \mathrm{m}$ and deteriorated the magnetic properties. These samples

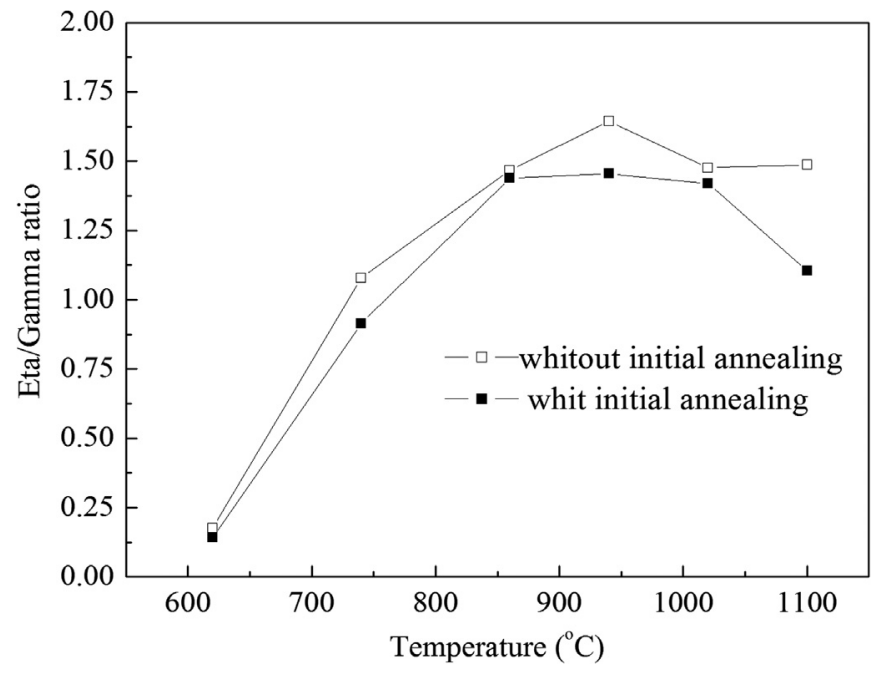

Fig. 9. Texture factor or Eta/Gamma ratio of samples with and without initial annealing as a function of the final annealing temperature.

with different grain sizes showed different textures in the cold rolling state and after the final annealing. The magnetic induction of the samples without initial annealing is always higher than the samples with initial annealing on grain growth stage. During the

\section{a}

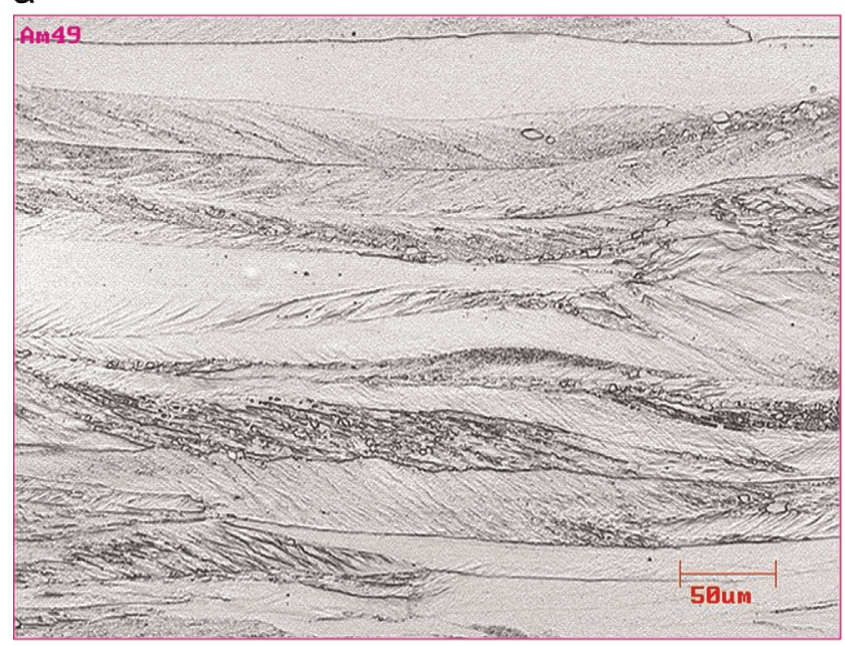

b

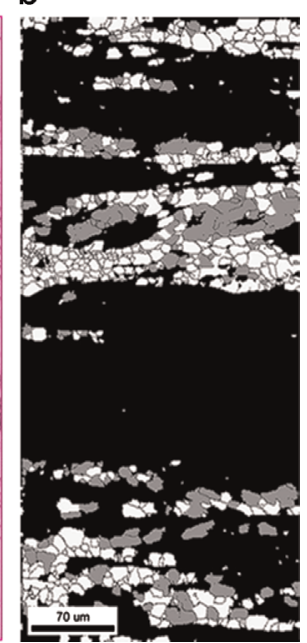

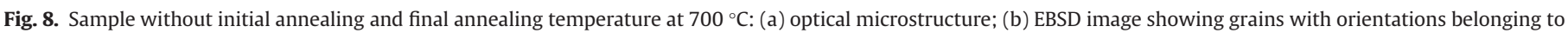
the Eta fiber (gray) nucleated in the shear bands. 


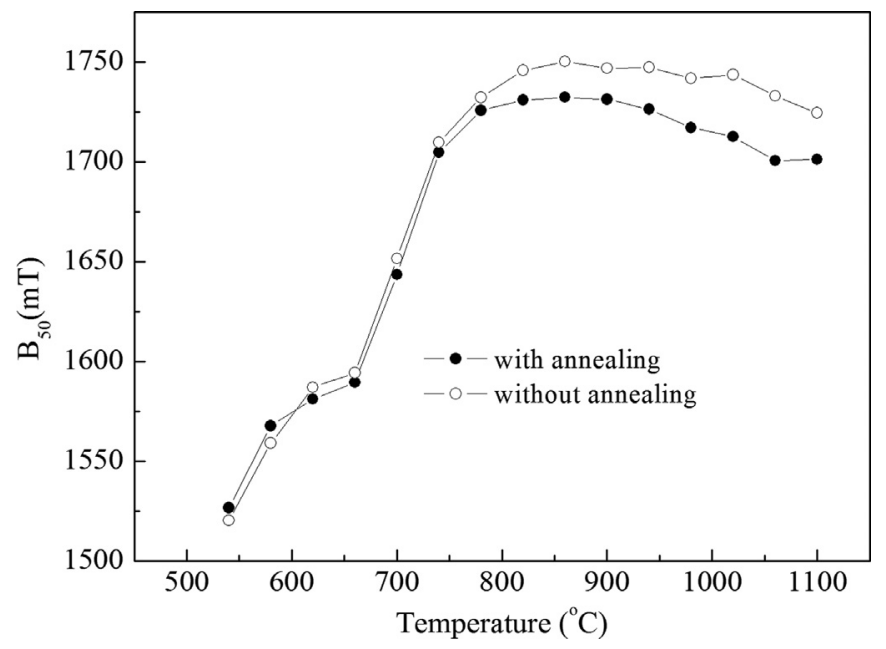

Fig. 10. Magnetic induction in samples with and without initial annealing according to the final annealing temperature.

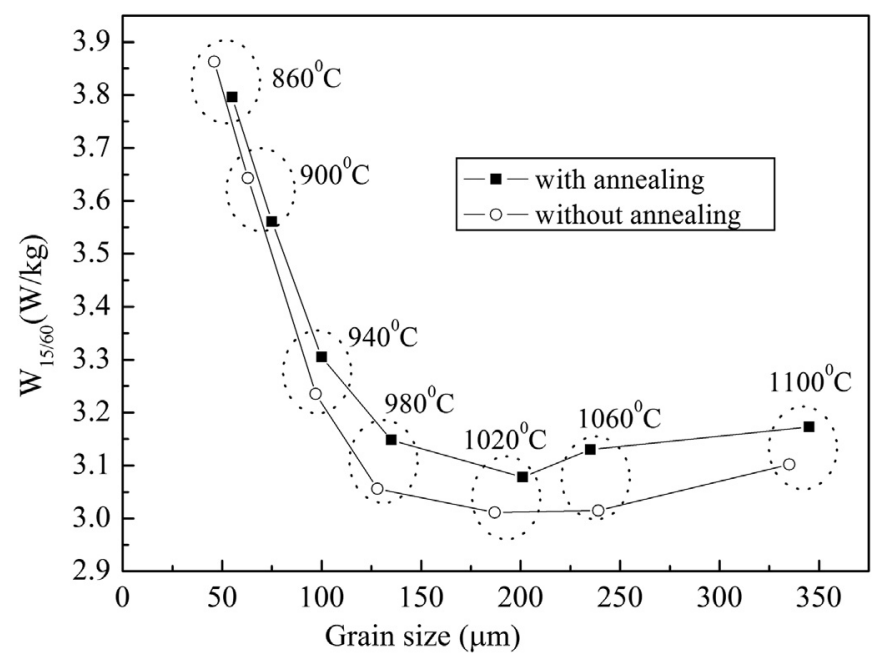

Fig. 11. Core loss $\left(W_{15 / 60}\right)$ in samples with and without annealing as a function of the final grain size. The final annealing temperatures are indicated.

stage of recrystallization and grain growth, the texture factor in the samples without initial annealing was always higher than the samples with initial annealing. The core loss in the samples without initial annealing is lower than in the samples with initial annealing at higher annealing temperatures on grain growth stage, due to the higher texture factor of samples without annealing.

\section{Acknowledgments}

The authors would like to thank Aperam South America and CAPES for supporting this study.

\section{References}

[1] F. Bohn, A. Gundel, F.J.G. Landgraf, A.M. Severino, R.L. Sommer, Magnetostriction in non-oriented electrical steels, Phys. B 384 (2006) 294-296.

[2] S.C. Paolinelli, M.A. Cunha, Effect of the annealing temperature on the structure and magnetic properties of 2\% Si steel, Mater. Res. 5 (2002) 373-378.

[3] S.C. Paolinelli, M.A. Cunha, Development of a new generation of high permeability non-oriented silicon steels, J. Magn. Magn. Mater. 304 (2006) 596-598.

[4] S.C. Paolinelli, M.A. Cunha, Effect of the annealing temperature on the structure magnetic properties of 3\% silicon non-oriented steel, J. Magn. Magn. Mater. 254-255 (2003) 379-381.

[5] J.T. Park, J.A. Szpunar, Evolution of recrystallization texture in nonoriented electrical steels, Acta Mater. 51 (2003) 3037-3051.

[6] R. Takanohashi, F.J.G. Landgraf, Effect of hot-band grain size and intermediate annealing on magnetic properties and texture of non-oriented silicon steels, J. Magn. Magn. Mater. 304 (2006) 608-610.

[7] T. Haratani, W.B. Hutchinson, I.L. Dillamore, P. Bate, Contribution of shear banding to origin of Goss texture in silicon steel, Met. Sci. 18 (1984) 57-65.

[8] S.C. Paolinelli, M.A. Cunha, A.B. Cota, The influence of shear bands on final structure and magnetic properties of 3\% Si non-oriented silicon steel, J. Magn. Magn. Mater. 320 (2008) 641-644.

[9] S.C. Paolinelli, M.A. Cunha, A.B. Cota, The influence of hot rolling finishing temperature on the structure and magnetic properties of $2.0 \% \mathrm{Si}$ nonoriented silicon steel, Mater. Sci. Forum 558-559 (2007) 787-792.

[10] S.S.F. de Dafé, S.C. Paolinelli, A.B. Cota, Influence of thermomechanical processing on shear bands formation and magnetic properties of a 3\% Si nonoriented electrical steel, J. Magn. Magn. Mater. 323 (2011) 3234-3238.

[11] H. Yashiki, T. Kaneko, Effect of hot-band annealing on anisotropy of magnetic properties in low-Si semi-processed electrical steels, J. Magn. Magn. Mater. 112 (1992) 200-202.

[12] S.C. Paolinelli, M.A. Cunha, Efeito da temperatura de acabamento sobre a estrutura e as propriedades magnéticas de um aço grão não orientado com 1,3\% Si, Tecnol. Metal. Mater. 1 (2004) 23-27.

[13] J.T. Park, J.A. Szpunar, Effect of initial grain size on texture evolution and magnetic properties in nonoriented electrical steels, J. Magn. Magn. Mater. 321 (2009) 1928-1932.

[14] K. Ushioda, W.B. Hutchinson, Role of shear bands in annealing texture formation in 3\% Si-Fe (111)[11-2] single cristals, ISIJ Int. 29 (1989) 862-867.

[15] M.A. Cunha, S.C. Paolinelli, Effect of the annealing temperature on the structure and magnetic properties of 2\% Si steel, Mater. Res. 5 (2002) 373-378.

[16] M.A. Cunha, S.C. Paolinelli, Low core loss non-oriented silicon steels, J. Magn. Magn. Mater. 320 (2008) 2485-2489.

[17] S.C. Paolinelli, M.A. Cunha, S.S.F. de Dafé, A.B. Cota, Study of the simultaneous effects of the hot band grain size and cold rolling reduction on the structure and magnetic properties of nonoriented 3\% Si steel, IEEE Trans. Magn. 48 (2012) 1401-1404 